common with the Solenostomidæ, the Fistulariidæ, the Aulostomidx, and the Centriscidæ, these families forming with the Lophobranchii a natural group, the "Solenichthyes " of Regan.

The scapular arch is cartilaginous to a much greater extent than is the case in other Teleosteans, but a small ossified scapula is to be found as well as a coracoid.

The three anterior vertebræ are immovably joined together, their neural arches being firmly bound by sutures with long dentations; in addition, the two anterior ones are fixed to the expanded clavicle. The vertebræ bearing the interspinous bones for the dorsal fin are provided with secondary transverse processes behind the primary ones, thus enlarging the surface which gives attachment to the powerful muscles of the dorsal fin, the chief agent in swimming.

After a paper by Dr. S. Hadwen on Texas fever in cattle, and its cure by the use of drugs, the day's programme closed with the reports of the special committees on grants.

The meeting on Monday, August 30 , was opened by Prof. A. B. Macallum, who read a paper, illustrated by numerous lantern-slides, on palæobiology and the age of the earth.

Prof. C. J. Patten followed with two papers:-(r) on the pre-nuptial plumage in Calidris arenaria, illustrated by lantern-views of the sanderling at different periods; (2) on the germinal disc in naturally incubated eggs of Passer domesticus. Due reflection of the facts that nests (or, in the case of those birds which make no nest, the soil on which the eggs are deposited) vary to an extraordinary extent in their heat-retaining properties; that the protecting egg-shells vary strikingly, not only in their thickness, but in their porosity and other structural peculiarities; and, lastly, that avian embryos vary to a considerable extent as regards their vitality when heat is withdrawn from the shell, has led the author to think that the method of studying avian embryology by means of the artificial incubator is not always the most trustworthy. He therefore described the changes which he observed during the first six hours in a clutch of naturally incubated eggs of the house-sparrow (Passer domesticus).

The next paper, on the rôle of visual function in animal and human evolution, was, in the absence of the author, Dr. G. M. Gould, taken as read.

Prof. S. H. Reynolds read a paper on the British Pleistocene Canidæ. Three species are found, the wolf, the fox, and the Arctic fox. There is no evidence of the existence in Britain in Pleistocene times of any animal that could be called a dog. The jaw described as Lycaon anglicus is thought by the author to be better regarded as a sometwhat abnormal wolf. While, apart from any difference in size, the skull of a fox is readily distinguished from that of a wolf or dog by the depressions in the postorbital processes of the frontals, it is extremely difficult, if not impossible, to find any valid distinctive character between dogs and wolves. The most useful character, for which we are indebted to Studer, is the orbitofrontal angle. $\mathrm{He}$ regards as belonging to wolves skulls in which this angle measures $40^{\circ}-45^{\circ}$, and as belonging to dogs skulls in which the angle is greater than $45^{\circ}$. The author's measurements, while confirming Studer's contention that the angle in question tends to be decidedly less in the wolf than in the dog, show that the distinction is not absolute, and cannot be relied on in all cases.

The programme for the last day of the meeting, Tuesday, August 3I, opened with a paper by $\mathrm{Mr}$. C. F. Rousselet, on the geographical distribution of Rotifera. The author showed that the results of recent investigations point more and more to the fact that the Rotifera enjoy a cosmopolitan distribution, which is not limited to continents, but extends to all places on the surface of the earth where suitable conditions prevail. Wherever search has extended in Europe, America, Africa, India, China, Australia, and even the north and south polar regions, the same genera, and even species, have been met with, and it is not possible to speak of any typical or peculiar rotatorian fauna for any continent, zone, or region.

The very erratic appearance of rare or uncommon species in widely separated places seems to show that distance is no obstacle to their distribution, provided only that they NO. 2086, VOL. $8 \mathrm{r}$ ] find suitable conditions. To account for such a distribution over the whole of the globe, it has been supposed that most species of Rotifera can be dried up and their bodies carried by the wind, as dust, for long distances, and then come to life again on landing in suitable surroundings. This Mr. Rousselet showed to be a very erroneous generalisation of the fact that a very few species of bdelloid Rotifera, and in particular Philodina roseola, are capable of secreting a gelatinous envelope in which they can resist drought for many months, and come to life again on being placed in water. The author's experience has shown him that the vast majority of rotifers die immediately on being dried, and do not revive after complete desiccation; but their eggs, and in particular their resting eggs, can stand a prolonged state of desiccation and also freezing, and can therefore readily be transported by the wind or by aquatic birds and other animals, and will hatch when deposited in suitable pools of water. In his opinion it is by this means that the cosmopolitan distribution of the Rotifera over the world has in the course of time been brought about.

Dr. J. Pearson read a paper on the processes of autotomy in the Crustacea, and Prof. H. Jungersen communicated an account, by Dr. J. Schmidt, of the distribution of the fresh-water eels (Anguilla) throughout the world.

The following papers were, in the absence of the authors, taken as read:-Dr. F. A. Dixey, on the parallelism between the nymphaline genera Adelpha and Chlorippe; and Mr. W. J. Dakin, histology of the eye of Pecten.

In the afternoon Mr. J. Stanley Gardiner delivered a lecture on coral-reefs, illustrated by numerous lanternviews.

Two resolutions were passed by Section $\mathrm{D}$ during the meeting at Winnipeg :-

(r) "The zoological section of the British Association wish to record their sense of the danger caused by the approach of the Norwegian rat, which threatens the wheat industry of western Canada, and to urge the Governments concerned to take immediate steps to organise the extermination of this dangerous pest."

(2) "In view of the enormous importance of the fisheries of Canada in connection with her prosperity and her rapidly developing position as the great source of the food supply of the Empire, and appreciating the danger of exhaustion which menaces certain of the fisheries, the members of the zoological section of the British Association for the Advancement of Science, now in meeting in Winnipeg, desire to congratulate both the Dominion and the Provincial Governments upon the work already accomplished in connection with the study of the food-fishes, upon the establishment of a marine biological station on both the Atlantic and Pacific coasts, and upon the cooperation with the Government of the United States in an International Commission from whose labours much may be expected. At the same time, the members of the section are of the opinion that further and more extensive efforts in all these directions are urgently needed if certain of the fisheries. notably that of the Pacific salmon, are to be maintained even at their present condition of productiveness. For the framing of satisfactory and effective regulations for the utilisation and conservation of the food-fishes a complete knowledge of their life-history is absolutely necessary, and the section desires to impress on the Grovernments concerned the immediate need for an extensive prosecution of investigations along this line, for greater facilities for the scientific study of the fisheries, especially those of the Pacific coasts, and for a continued cooperation of the Dominion Government with the governments of the provinces and also those of the United States in all efforts looking towards the conservation of the fisheries, one of the most valuable natural resources of Canada."

\section{GEOGRAPHY AT THE BRITISH ASSOCIATION}

THIS section was presided over this year by Colonel Sir Duncan A. Johnston, K.C.M.G., C.B., formerly director-general of the Ordnance Survey of the United Kingdom, and, as usual, the opening address dealt' with matters of which the president had been made intimately cognisant through his life-work. After briefly referring to 
the additions made to geographical knowledge during the year by the journeys of Dr. Sven Hedin, Dr. Aurel Stein, and Lieut. Shackleton, Sir Duncan Johnston devoted the bulk of his address to the subject of topographical maps, considering specially the preliminary triangulation for such maps, the methods of detail survey, the scale of the map, the scale of the field survey, the methods of representing details on the map, and the methods of reproduction. The address was printed in Nature of September 9.

The remainder of the first morning sitting of the section was taken up with the reading of papers by Miss Luella A. Owen, of St. Joseph, Mo., on floods in the great interior valley of North America; by $\mathrm{Mr}$. James White, head of the Geographical Department of the Dominion of Canada, on the nomenclature of the islands and lands of Arctic Canada; and Dr. Robert Bell, formerly head of the Geological Survey of Canada, on the Hudson Bay route in its present aspect. The first of these papers, written by an eye-witness of the flood of 1903, when at the end of May and the beginning of June the valley at Kansas City "was filled from bluff to bluff with the turbulent muddy waters, which on June 2 completely submerged the entrances to the main waiting-room of the Union station," gave in a compact form an account of the conditions which produce floods in the region in question and of the diversified character of their consequences, and then considered the possibility of their future control as a subject of vital interest to the United States, and one involving a careful examination of the methods of control in order to avoid the possibility of bringing about evils more disastrous than the floods themselves. Mr. White's paper necessarily consisted entirely of details, but as these are of no little interest in the history of geography, geographers will be glad to learn that they will be made available in the pages of the Geographical Journal. In the third of the morning papers Dr. Bell reiterated the views he has long held and urged as to the practical importance of the Hudson Bay route for the development of the north-west of Canada, emphasising on this occasion the urgency of the problem in view of the rapidity with which that development is taking place and the effect which it may be expected to have in promoting more intimate commercial relations between that region and the mother country.

No separate meetings of Section $\mathrm{E}$ were held in the afternoons, but the afternoon of Thursday, August 26 , was devoted to a joint meeting of that section with the subsection on agriculture, at which a paper contributed to Section E by Prof. A. P. Brigham, secretary of the American Association of Geographers, on the development of wheat culture in North America, was followed by one contributed to the subsection on agriculture by Prof. Mavor, of Toronto, on the agricultural development of Canada, I904-9. The first of these papers will be published in full in the annual report of the association, as well as in the Geographical Journal. Here, therefore, it will be enough to say that it laid stress on the enormous possibilities still remaining for the expansion of wheat production even in the United States, directing attention, among other things, to the large production of wheat relatively to population in some States not generally thought of as wheat States, such as Maryland, which this year produced eleven bushels of wheat per head. Prof. Mavor's paper was a continuation of his well-known report to the Board of Trade on the same subject, coming down to the year 1904, and, like it, protested against some of the more sanguine estimates of the possibilities of wheat production in Canada, although he admitted that his estimates of 1904 ought to be increased. An animated discussion followed the reading of the two papers. The prevailing note of that discussion was sanguine, both as to the possibility of enormously extending the area under wheat in North America and increasing the production in the area already placed under that crop. Major Craigie, chairman of the subsection on agriculture, directed attention, however, to the dependence of that increase on the distribution of population, and thus implicitly raised the question of the future rate of increase of wheat production in North America, and the possibility of maintaining that increase without a concurrent advance in prices. NO. 2086, VOL. 8I]
The first paper read in Section E: on Friday; August 27, was also by Prof. Mavor-a summary sketch of the economic geography of Canada. Mr. J. Stanley Gardiner, F.R.S., then gave a semi-popular account, illustrated by many beautiful lantern-slides, of the Seychelles, a subject on which he sent a report to the association as secretary of the committee for the investigation of the Indian Ocean appointed by the association. Two papers relating to physical geography followed. The first of these, by Prof. W. H. Hobbs, of the University of Michigan, Ann Arbor, developed an interesting theory of the cycle of Alpine glaciation, showing how many of the phenomena of glacial erosion found their explanation in the alternation of the conditions bringing about the advance and retreat of glaciers. This paper will also appear in the pages of the Geographical Journal. The other was by Prof. Dodge, of Columbia University, on the formation of arroyos in adobe-filled valleys in the south-western. United States. The origin of these arroyos, or wadis, as they would be termed in arid regions frequented by Arabic-speaking peoples, was attributed in this paper to the introduction of sheep, the grazing of the herbage by which in gently sloping valley, floors first gave the water an opportunity to become concentrated in streams instead of running off the surface in sheets, a theory which confirms an observation of the Navajos, the native race of the region. The last paper read that morning was by Mr. Lawrence J. Burpee, of the Carnegie Library, Ottawa, on the water route from Lake Superior to the westward. Of the three routes, that of the Kaministikwia, that by Grand Portage, and that by way of Lake Nipigon, the first-mentioned was the first to be discovered; but was neglected and forgotten after the discovery of the Grand Portage route, and remained forgotten until the Canadians ascertained that Grand Portage lay in the territory of the United States. Search for another route led to the re-discovery of that by the Kaministikwia, and rendered the nearly simultaneous discovery of the Nipigon route of no practical importance.

Two hours of the morning of Monday, August 30, were taken up with a discussion on the teaching of geography in secondary schools at a joint meeting of Sections $\mathrm{E}$ and $\mathrm{L}$, held at the meeting place and under the chairmanship of the president of the latter section. The discussion was opened by an informatory and helpful paper by Prof. R. E. Dodge, of Columbia University, New York, and followed by one (read in the absence of the writer by the recorder of Section E) by Dr. C. H. Leete, principal of the Sachs School for Girls, New York, who has been engaged in the secondary teaching of geography for upwards of a quarter of a century. Several professors and teachers of geography took part in the discussion that followed, and almost all these coincided with the view expressed by Prof. Dodge, that the teacher of geography should look upon it as his business to let the relation of the earth to man dominate his presentation of the subject. The remainder of the morning was taken up with a lecture by Mr. A. O. Wheeler, president of the Alpine Club of Canada, on some characteristics of the Canadian Rockies, which attracted a larger audience in Section $E$ than was assembled on any other occasion during the meeting.

The meeting on Tuesday, August $3 \mathrm{r}$, was opened by a carefully prepared and instructive paper on the influence of mechanical transportation upon the framework of cities, by $\mathrm{Mr}$. George E. Hooker, civic secretary to the City Club of Chicago. It was, unfortunately, read to a very meagre audience, but there is reason to hope that it will appear somewhere in a permanent form. Prof. A. P. Coleman, of Toronto University, followed with a paper on the Yellowhead Pass and Mount Robson, an adjacent peak, the highest in the Canadian Rockies. Prof. J. W. Gregory, of Glasgow, then gave a brief but very illuminating account of the remarkable success which has attended the replacement of kanaka by white labour on the sugar plantations of Queensland. The last two papers read that morning furnished two illustrations of the action of waves and currents in bringing about changes in shore-lines. The first was by Prof. Douglas W. Johnson, of Harvard University, and dealt with the physical history of Nantasket 
Beach, a spit running northwards from the east end of the south shore of Boston Harbour. This beach consists of sand, gravel, and cobbles deposited by wave action between several drumlins which formerly existed as islands, and with the aid of a series of lantern-slides the reader of the paper showed how the form of the beach ridges and their relation to abandoned marine cliffs on the drumlins prove the former existence of several drumlin islands now entirely destroyed by the sea. The second of these papers was by Dr. F. P. Gulliver, secretary to the geographical and geological section of the American Association for the Advancement of Science, and dealt with what he called the Wauwinet-Coscata Tombolo, Nantucket, Mass. The term tombolo, the Italian for a "pillow," applied in Italy to the low ridges or necks connecting Mt. Argentario with the mainland, Dr. Gulliver proposes as a general designation for such necks. The paper described and illustrated by lantern-views the opening of the neck referred to by a storm in December, 1896, when a channel navigable by small boats was formed, and the closing of this channel by waves and currents nearly twelve years laterNovember, 1908 .

Some of the most interesting papers read in the section during the meeting were reserved for the last day, Wednesday, September 1, which was so far fortunate that the winding up of several other sections on the previous day allowed of the gathering of a larger audience in this section than was present on most of the other mornings. The first two papers were by $\mathrm{Mr}$. James White, of Ottawa, one of them on the progress of the geographical knowledge of Canada from 1497 to I909, the other on the economic development of Canada from I867 to igog. The subject treated of in the first of these two papers, which will appear in full in the Geographical Journal, was illustrated by a number of maps for different dates, for the most part at intervals of fifty years, illustrating for the earlier years the extent of exploration within the territory of the present dominion, and for the later years the extent of territory that remained unexplored. The subject of the second was illustrated mainly by means of statistical diagrams. These were followed by a very interesting paper by $\mathrm{Mr}$. J. B. Tyrrell, formerly of the Geological Survey of Canada, on a remarkable forgotten, or nearly forgotten, geographer, Mr. David Thompson, a native of London but of Welsh parentage, who, in the latter part of the eighteenth and the early part of the nineteenth century, travelled more than fifty thousand miles in the western wilds of Canada, making surveys wherever he went, and producing a map which was for many years the only one available, and was distinguished by such accuracy as to induce the reader of the paper to claim for its compiler the designation of the greatest practical land geographer who had ever lived. This paper also will appear in full in the Geographical Journal. Dr. L. A. Bauer, director of the department of terrestrial magnetism at the Carnegie Institution of Washington, then gave a brief general account of the progress of the general magnetic survey of the earth in recent years, a subject dealt with more fully in a paper read by the same author to Section A. It may here be mentioned, however, that the author stated that since April I, 1904, the declination and dip of the magnetic needle and the intensity of the magnetic current had been determined at some 900 land stations in different parts of the world and a general magnetic survey of the Pacific Ocean had been made, in the course of which the nonmagnetic cruiser Galilee had made cruises amounting to about 60,000 nautical miles. The last paper read before the section was by Mr. Allorge, of the Oxford School of Geography, on the eastern (Tunisian) Atlas Mountains, their main structural and morphological features, a paper embodying the results of a journey made by Mr. Allorge and a companion in Tunis last spring.

It may be mentioned, in conclusion, that a somewhat dramatic incident marked the close of the meeting of this section. The last paper had been read, the audience had withdrawn, and the two secretaries, after winding up the work of the meeting, were just about to leave also, when they were summoned to the telephone to be informed of the reported reaching of the North Pole by Dr. Cook.

No. 2086, VOL. 8I]

\section{PHYSIOLOGY AT THE BRITISH ASSOCIATION.}

THE president's address on "The Physiological Basis of Success," as distinguished from simple survival, has already appeared in NATURE (September 23, p. 384).

The report of the committee on Anæsthetics formed the basis of an interesting discussion. Presented by $\mathrm{Dr}$. Waller, the chairman, the report gave, in the first instance, a summary of the work done during the year by the members of the committee, each of whom added appendices on the particular branch of the subject they had investigated. Appendix $i$. gave the results in clinical practice of Drs. Hewitt and Blumfeld, who employed a mixture of two parts of chloroform and three parts of ether; this they consider to be safer than chloroform alone when given by the open method.

Appendix ii. described Dr. Waller's chloroform balance, which shows at a glance the percentage of chloroform given to the patient. Appendices iii, and iv. summarise Dr. Waller's results on the comparative anæsthetising power of chloroform, ether, and alcohol, and Appendix vi., by Drs. Waller and Symes, gave a method of intravenous anæsthesia which can be used for the basis of a similar calculation. The very important results are reached that i gram of chloroform is equivalent to 8 grams of ether and 32-40 grams of alcohol, according to the method used for the calculation. Further, the effect of mixtures of anæsthetics is that of the sum of the constituents. As the anæsthetic action of ether (and still more of alcohol) is so much less than that of chloroform, a mixture of ether and chloroform will behave in practice like dilute chloroform, so far as the experiments have gone.

In the discussion that followed all the speakers expressed their appreciation of the scientific value of the determinations that had been made. Dr. N. H. Alcock referred to the excellent results that had been obtained by the administration of known percentages of chloroform vapour, and summarised the work that had been done on the individual variations in susceptibility to the drug. He regretted that the case of sudden death under a mixture of chloroform and ether (Times, August 5) had supplied such an inauspicious comment on Appendix i. of the report.

Prof. A. R. Cushny considered that the results obtained by Messirs. Buckmaster and Gardiner were of great importance to the general theory of pharmacological acţion. He considered that as the concentration of chloroform in the blood of patients who had succumbed during anæsthesia had not yet been ascertained, it was possible that the concentration was not unduly high.

Prof. W. T. Porter suggested that the unhappy result in some of these cases could not at present be averted by the most skilful anæsthetists, and that the cause might be sought in the hyper-irritability of the heart and vasomotor apparatus.

Dr. Webster contributed a paper on the use of atropine and allied drugs in conjunction with anæsthetics, giving the results of numerous experiments. The conclusion reached was not favourable to the use of drugs of this class in conjunction with a general anæsthetic.

Prof. A. B. Macallum read two papers on the inorganic constituents in the blood of fishes, the first dealing with the osmotic pressure and the second with the relations of the inorganic salts to one another. $\mathrm{He}$ also read a third paper, on the inorganic composition of the blood in puerperal eclampsia, in which he pointed out the greater preponderance of magnesium, and especially potassium, in comparison with sodium.

A group of papers on the tracts in the spinal cord was furnished by Dr. Page May and Prof. Sutherland Simpson. Dr. Page May, who exhibited microscopical specimens and lantern-slides, gave a further description of a descending tract discovered by him, and which he names the "posteroseptal tract." The origin and course, as determined by Wallerian degeneration and by retrograde chromatolysis, is from a joint region of the optic thalamus and corpora quadrigemina along chiefly the mesial fillet into the posterior column of the spinal cord, where it lies symmetrically on either side in close contact with the posterior septum, 